\title{
Phenotypic heterogeneity may occur in congenital fibrosis of the extraocular muscles
}

\author{
A C Reck, R Manners, E Hatchwell
}

Southampton Eye Unit, Southampton General Hospital, Southampton A C Reck

R Manners

Department of Medical Genetics, Princess Anne Hospital,

Southampton E Hatchwell

Correspondence to: Miss A C Reck, Southampton Eye Unit, Southampton General

Hospital, Southampton.

Accepted for publication 22 January 1998

Table 1 Ophthalmological details of affected individuals

\begin{tabular}{|c|c|c|c|c|c|}
\hline Cases & $\begin{array}{l}\text { Corrected } \\
\text { visual } \\
\text { acuity }\end{array}$ & $\begin{array}{l}\text { Palpabral } \\
\text { aperture } \\
(\mathrm{mm})\end{array}$ & $\begin{array}{l}\text { Levator } \\
\text { function } \\
\text { (mm) }\end{array}$ & Aberrant movements & $\begin{array}{l}\text { Chin } \\
\text { elevation }\end{array}$ \\
\hline \multirow[t]{2}{*}{$\begin{array}{l}\text { Family } 1 \\
\text { case } 1.1\end{array}$} & R: $6 / 12$ & 6 & 0 & $\begin{array}{l}\text { Convergence on upgaze, } \\
\text { adduction of the left eye. }\end{array}$ & yes \\
\hline & L: $6 / 12$ & 6 & 0 & & \\
\hline \multirow[t]{2}{*}{$\begin{array}{l}\text { Family } 2 \\
\text { case } 2.1\end{array}$} & $\mathrm{R}: 6 / 6$ & 8 & 1 & $\begin{array}{l}\text { Convergence on up and } \\
\text { down gaze }\end{array}$ & yes \\
\hline & L: $6 / 6$ & 8 & 1 & & \\
\hline \multirow[t]{2}{*}{ case 2.2} & $\mathrm{R}: 6 / 60$ & 4 & 3 & $\begin{array}{l}\text { Bilateral nystagmoid } \\
\text { movements on upgaze }\end{array}$ & yes \\
\hline & $\mathrm{L}: 6 / 6$ & 4 & 4 & & \\
\hline \multirow[t]{2}{*}{ case 2.3} & R: HM & 3 & 0 & $\begin{array}{l}\text { Bilateral convergence on } \\
\text { upgaze }\end{array}$ & yes \\
\hline & L: $6 / 18$ & 4 & 0 & & \\
\hline \multirow[t]{2}{*}{$\begin{array}{l}\text { Family } 3 \\
\text { case } 3.1\end{array}$} & R: $6 / 18$ & 5 & 1 & $\begin{array}{l}\text { Bilateral convergence on } \\
\text { upgaze }\end{array}$ & yes \\
\hline & L: $6 / 12$ & 3 & 0 & & \\
\hline \multirow[t]{2}{*}{ case 3.2} & R: $6 / 18$ & 4 & 4 & $\begin{array}{l}\text { Bilateral convergence on } \\
\text { up and downgaze, } \\
\text { depression of left eye on } \\
\text { left gaze }\end{array}$ & yes \\
\hline & L: $6 / 18$ & 4 & 2 & & \\
\hline \multirow[t]{2}{*}{$\begin{array}{l}\text { Family } 4 \\
\text { case } 4.1\end{array}$} & $\mathrm{R}: 6 / 12$ & 6 & 11 & $\begin{array}{l}\text { Nystagmoid movements } \\
\text { in any attempted } \\
\text { direction of gaze }\end{array}$ & yes \\
\hline & L: $6 / 12$ & 6 & 11 & & \\
\hline \multirow[t]{2}{*}{ case 4.2} & $\mathrm{R}: 6 / 12$ & 5 & 0 & $\begin{array}{l}\text { Abduction of right eye } \\
\text { on left gaze }\end{array}$ & yes \\
\hline & L: $6 / 60$ & 5 & 0 & & \\
\hline \multirow[t]{2}{*}{ case 4.3} & R: 6/9 & 5 & 0 & None & yes \\
\hline & L: $6 / 6$ & 4 & 0 & & \\
\hline \multirow[t]{2}{*}{ case 4.4} & $\mathrm{R}: 6 / 6$ & 5 & 1 & $\begin{array}{l}\text { Synergistic divergence on } \\
\text { attempted lateral gaze }\end{array}$ & no \\
\hline & L: $6 / 9$ & 5 & 1 & & \\
\hline
\end{tabular}
traction syndrome, and congenital fibrosis of the inferior rectus. The purpose of this study was to identify families with CFEOM in this geographical region in order to perform a study of the clinical presentation of this disorder and to estimate its minimum prevalence in the population.

Methods-Four families were identified with CFEOM in the Wessex region from whom a full history with a pedigree was obtained. All individuals underwent ophthalmological examination.

Results/conclusion-This study shows that several of the CFEOM entities can be present within one family suggesting that these are variants of the same condition. It is suggested that subclassification is, therefore, not appropriate. The minimum prevalence of this disorder was found to be $1 / 230000$

Backgroundlaims-Congenital fibrosis of the extraocular muscles (CFEOM) is an autosomal dominant, non-progressive disorder characterised by congenital ptosis and external ophthalmoplegia. CFEOM has previously been divided into several clinical entities; general fibrosis syndrome, strabismus fixus, vertical re-

\section{(Br F Ophthalmol 1998;82:676-679)}

Congenital fibrosis of the extraocular muscles (CFEOM) is an inherited, non-progressive disorder characterised by congenital ptosis and external ophthalmoplegia. The syndrome was first described by Heuk in $1879^{1}$ who showed on postmortem examination that the extraocular muscles were fibrotic and abnormally inserted. The condition was described in detail by Brown in $1950 .^{2}$ Laughlin reported the condition in at least four generations in $1956 .^{3}$ Since then regular additional reports have occurred in the literature ${ }^{4-14}$ describing approximately 100 cases.

The pattern of inheritance is autosomal dominant with descriptions of male to male transmission. Sporadic cases have been described. Recently, possible linkage of CFEOM to markers in the pericentromeric region of chromosome 12 has been shown. ${ }^{15}{ }^{16}$

The purpose of this study was to identify families with CFEOM in this geographical region in order to perform a clinical study and estimate the minimum prevalence of this disorder in the population.

\section{Methods}

All ophthalmologists in the region were contacted and asked for details of any patients who might have CFEOM. All patients contacted were willing to participate in the study and were visited at home by a clinical geneticist (EH) and an ophthalmologist (ACR). A full history was obtained and a pedigree constructed (Fig 1). Both affected and unaffected individuals underwent ophthalmological examination (Tables 1 and 2).

\section{FAMILY 1}

Case 1.1

A healthy 54 year old woman was referred for evaluation of her bilateral ptosis which was causing marked chin elevation. She had undergone ptosis and squint surgery when age 11 years.

\section{FAMILY 2}

\section{Case 2.1 (Fig 2)}

A 13 year old boy was referred for ptosis surgery. He was generally fit and well. At the age of 2 he had undergone bilateral anterior levator resections. Preoperative forced duction tests confirmed tight inferior recti. Both inferior recti and the superior obliques were 

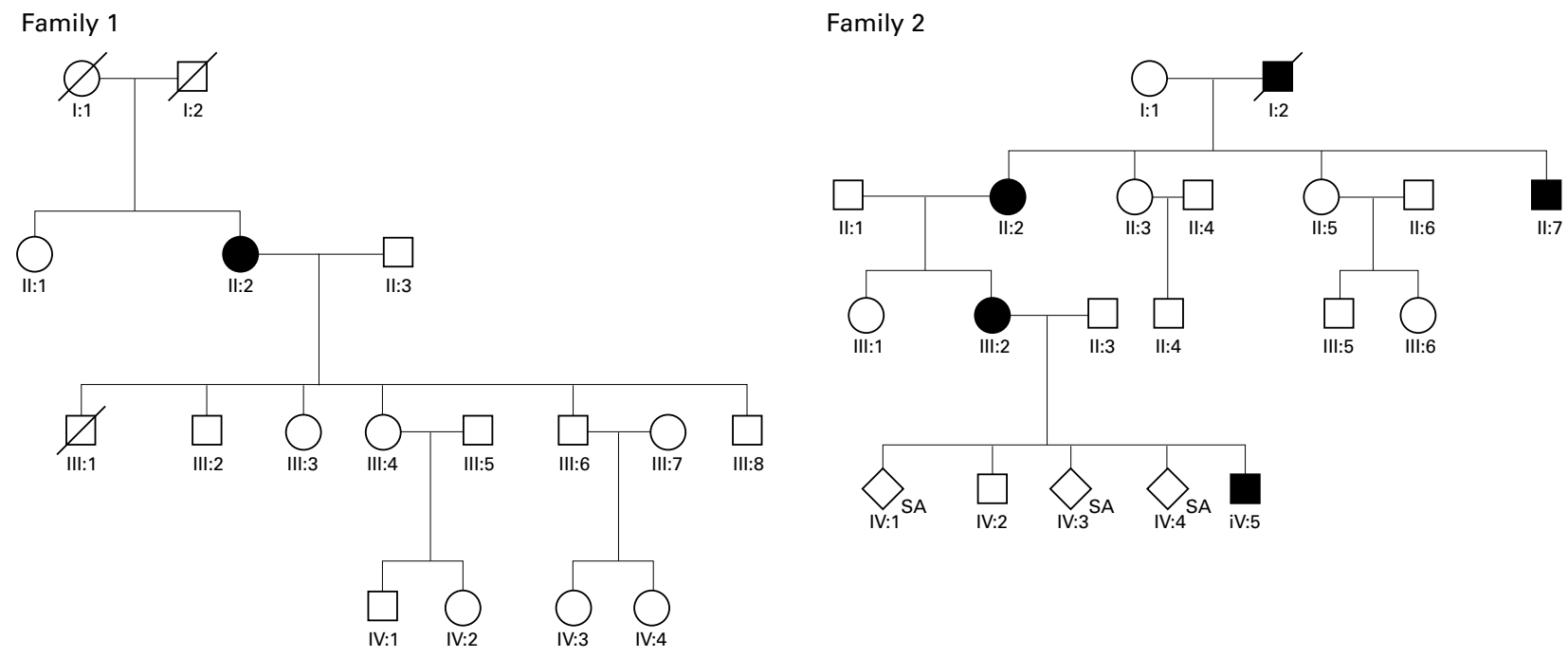

Family 3

Family 4
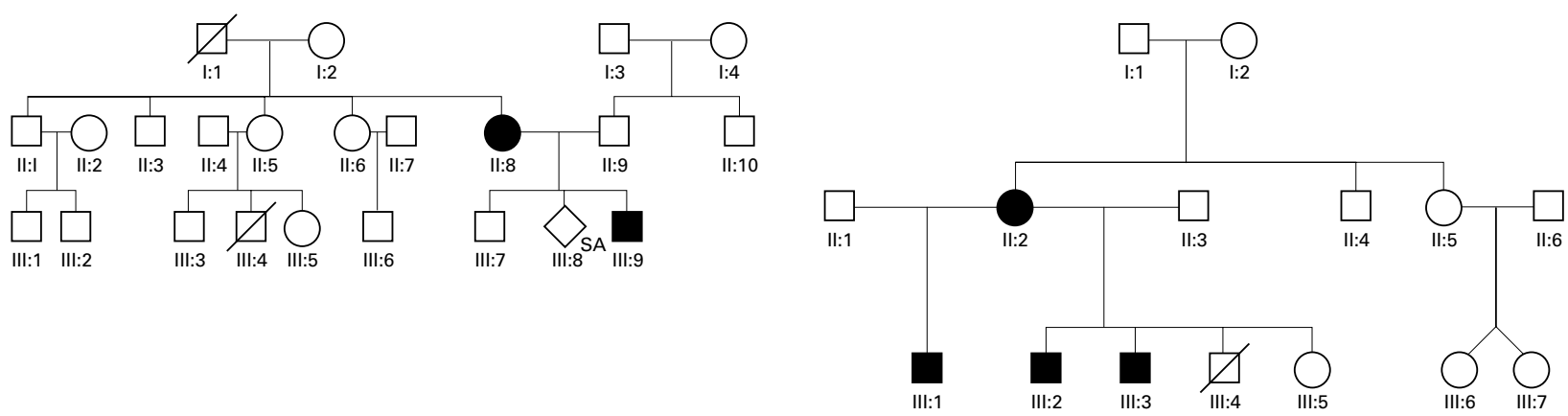

Figure 1 Pedigrees of four families with congenital fibrosis of extraocular muscles, consistent with autosomal dominant inheritance, although there are no instances of male to male transmission.

recessed Subsequently he underwent bilateral brow suspension with autogenous fascia lata. Postoperatively his abnormal head posture was improved.

Case 2.2 (Fig 3)

A 44 year old woman was fit and well apart from mild arthritis. She had undergone a left brow suspension aged 9 months.

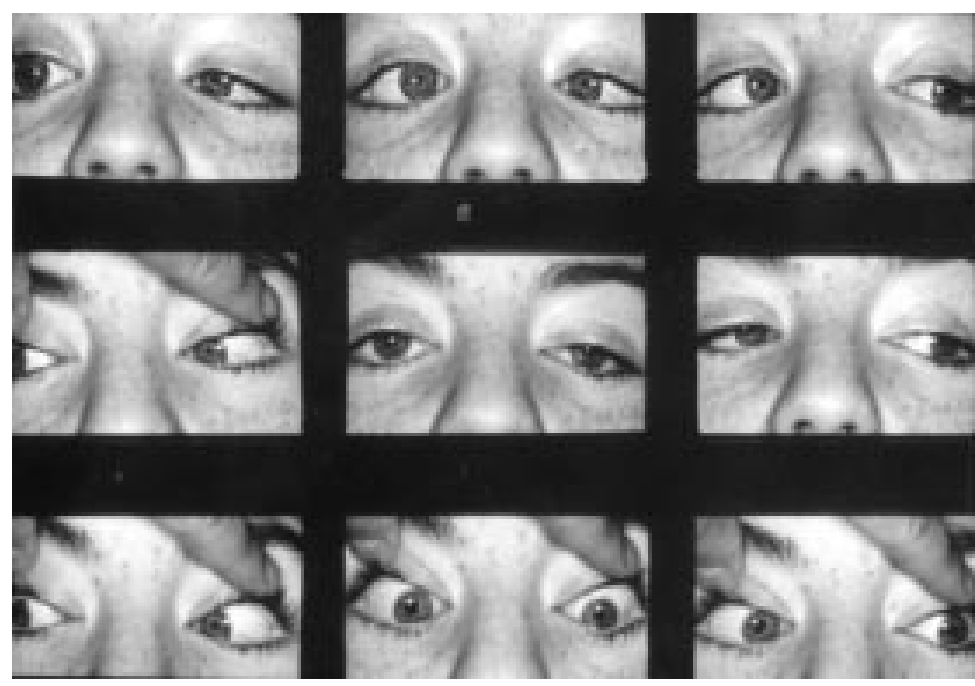

Figure 2 Case 2.1.
Case 2.3 (Fig 4)

A 63 year old woman, was fit and well. She had been under the care of an ophthalmologist as a child and had undergone previous surgery which was unknown.

Family 2 shows that several of the CFEOM entities may be present within one pedigree. Cases 2.1 and 2.2 are typical examples of congenital fibrosis of the inferior recti while case 2.3 would be classified as the general fibrosis syndrome.

FAMILY 3

Case 3.1

A 5 year old boy was referred. Apart from problems with speech and language development he was otherwise fit and well.

\section{Case 3.2}

A 30 year old woman was fit and well. She had undergone unspecified surgery to both upper lids as a child.

Both affected members of family 3 are phenotypically very similar and would be classified as having the generalised fibrosis syndrome.

\section{FAMILY 4}

Case 4.1

A 30 year old woman with good general health had been seen as a child by an ophthalmologist, but had never had any treatment. 
Table 2 Eye movements

Case 1.1
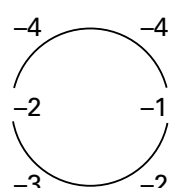
LET

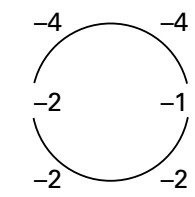

Case 2.1

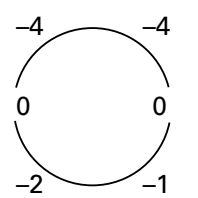
LET
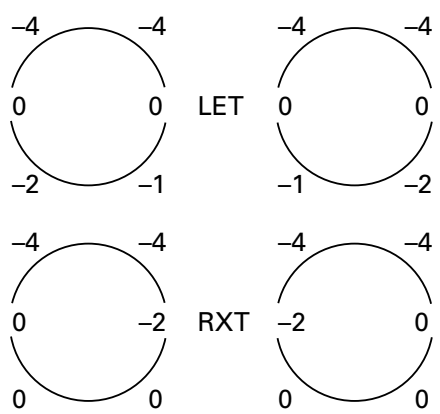

$\mathrm{RXT}$
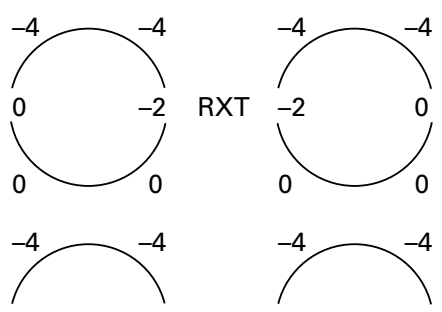

Case 2.3

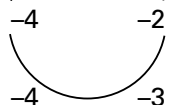

RE

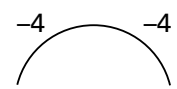

$-3-4$
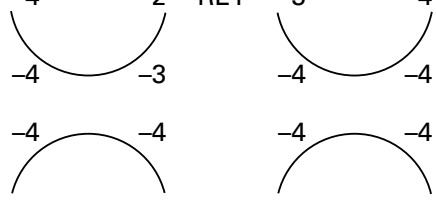

$-2$

Case 3.1

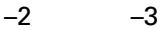

$\mathrm{RXT}$
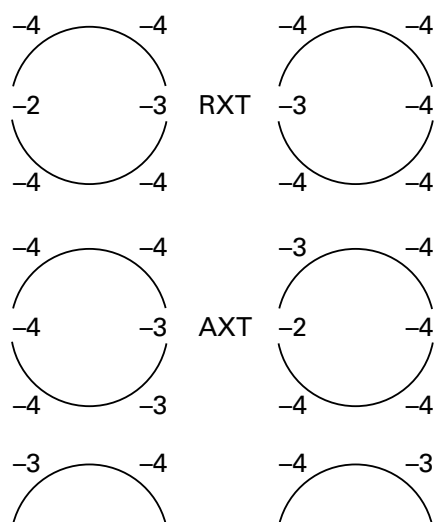

Case 4.1

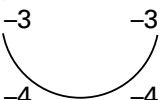

$A X$
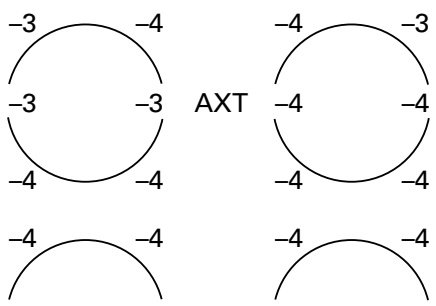

Case 4.2

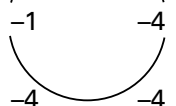

AXT
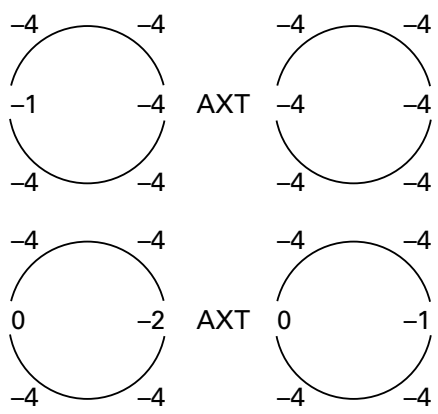

AXT
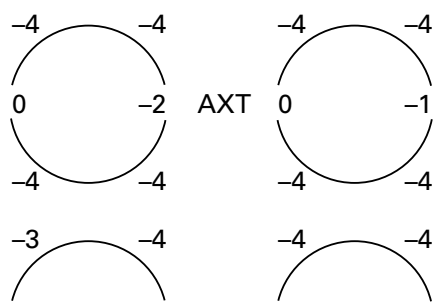

Case 4.4

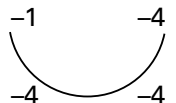

AXT

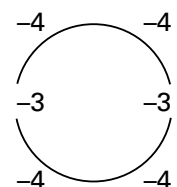

Case 4.2

A 12 year old boy was attending a school for children with emotional behavioural problems, but was otherwise fit and well. At 18 months he had undergone bilateral ptosis and squint surgery. At age 12 he had underwent bilateral brow suspension and inferior rectus tenectomies.

Case 4.3

A healthy 8 year old boy, had undergone bilateral brow suspension with donor fascia lata at age 2. Postoperatively, he developed an abscess on the left side causing drooping of the left lid, and the right lid gradually dropped over the following year. At age 4 he had a repeat bilateral brow suspension with donor fascia lata and $5 \mathrm{~mm}$ recessions of the inferior recti. Postoperatively the left upper lid was still low and a further brow suspension with donor fascia lata was performed on the left side 18 months later resulting in a good lid position.

Case 4.4

A 5 year old boy had tracheomalacia but was otherwise fit and well. At age 1 he had had bilateral brow suspension with donor fascia lata and bilateral inferior rectus recessions. Postoperatively his abnormal head posture was improved. At age 3 he had a repeat bilateral brow suspensions with donor fascia lata and bilateral inferior rectus tenectomies to treat his remaining chin up head posture.

Family 4 all show markedly reduced vertical movements, with variable involvement of the horizontal muscles and levator muscle.

\section{Results/discussion}

We have found the minimum prevalence of CFEOM in the Wessex region (population 2.3 million) to be $1 / 230000$.

CFEOM has been subclassified into several similar syndromes - general fibrosis syndrome, strabismus fixus, vertical retraction syndrome, and congenital fibrosis of the inferior recti with or without ptosis.

These are all static disorders and probably represent a developmental defect of the extraocular muscles. Histopathological examinations show a combination of fibrous tissue replacing muscle, adhesions between muscle and Tenon's capsule, absent muscles in some cases and anomalous muscle insertions. Occasionally the muscles look normal even on microscopic examination. ${ }^{4}{ }^{14}$

Recently computed tomography has been used to investigate this condition. Gillies et al ${ }^{11}$ described a family with five affected members. Computed tomography showed reduction in the size of the extraocular muscles particularly the superior recti as well as abnormal globe shape (two patients) and cranial ventricular asymmetry (three patients). Hupp et $a l^{9}$ likewise found atrophy of involved muscles on computed tomography.

General fibrosis syndrome ${ }^{2}$ has been characterised as extensive involvement of all the ocular muscles with marked ptosis present in all patients. The eyes are fixed in a downward position and the patients adopt a chin up head position to compensate. Often aberrant movements occur on attempts to move the eyes into the restricted field of vision. Strabismus fixus is 


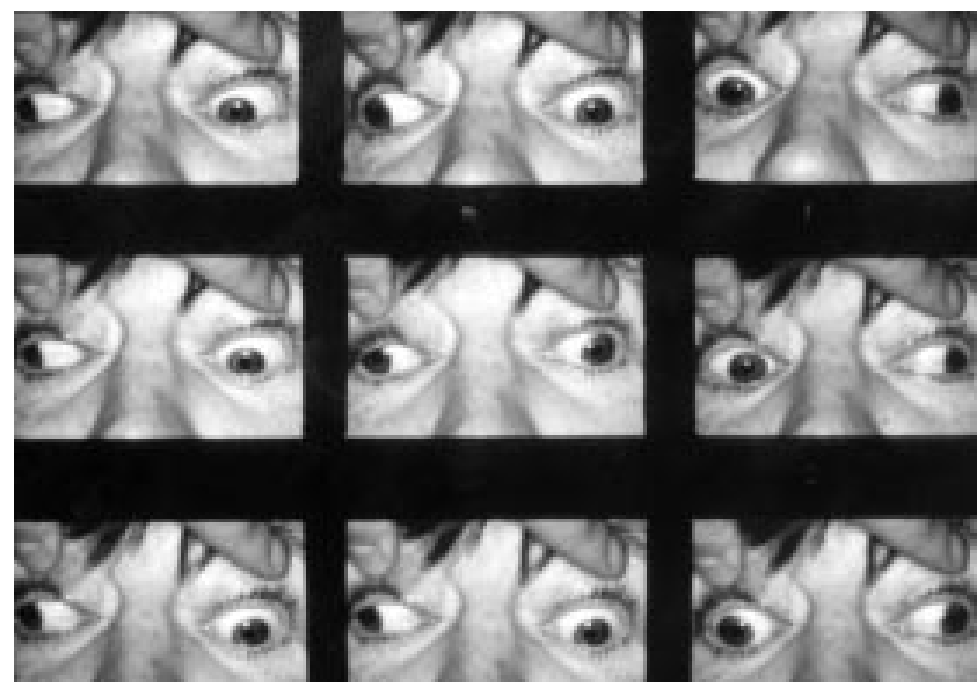

Figure 3 Case 2.2.

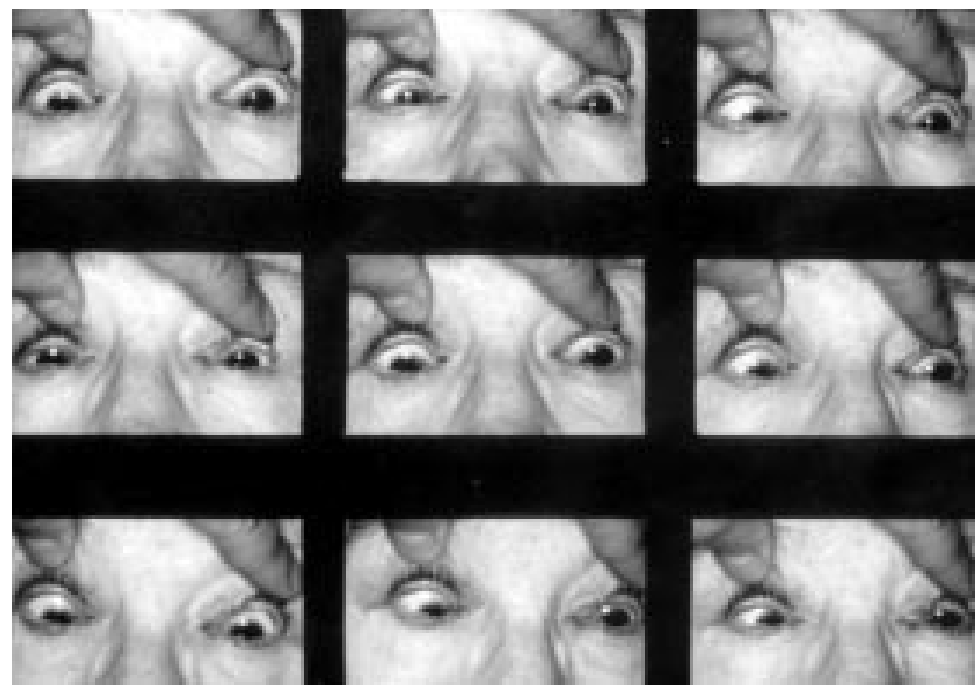

Figure 4 Case 2.3. been adopted. In addition, our fourth family also reflects the intrafamilial heterogeneity that is possible. All members had markedly reduced vertical moments but the involvement of the horizontal muscles varied greatly between family members, as did the involvement of the levator muscle. Further evidence for phenotypic heterogeneity is to be found in case 4.1, who had extensive involvement of all the extraocular muscles consistent with generalised fibrosis but in whom the levator muscle was minimally affected.

Our families show that CFEOM is characterised by a varying clinical picture depending on the number of muscles involved. The inferior rectus is most prone to maximal involvement causing the eyes to be fixed in downgaze. Ptosis is almost invariably present.

In summary, we believe that CFEOM should be used to describe a condition with variable involvement of the extraocular muscles, and that attempts at further subclassification of this condition on purely clinical criteria may not be justified. Future classification may be aided by improved knowledge of the molecular basis of this condition ${ }^{15} 16$ but it is possible that the genotype/phenotype correlation will not always be strong, as demonstrated in our second family.

1 Heuk G. Ueber angeborenen veterbten Beweglichkeitsdefekts der Augen. Klin Monatsbl Augenheilkd 1879;17:3253.

2 Brown HW. Congenital muscle abnormalities. In: Allen JH, ed. Strabismus ophthalmic symposium. St Louis: CV Mosby, 1950:229-33.

3 Laughlin RC. Congenital fibrosis of the extraocular muscles a report of six cases. Am f Ophthalmol 1956;41:432-8.

4 Harley RD, Rodrigues MM, Crawford JS. Congenital fibrosis of the extraocular muscles. F Pediatr Ophthalmol Strabismus 1978;15:346-58.

5 Holmes WJ. Hereditary congenital ophthalmoplegia. Trans Am Ophthalmol Soc 1956;53:245.

6 Am Ophthalmol Soc 1956;53:245. Hansen E. Congenital general fibrosis
muscles. Acta Ophthalmol 1968;46:469.

7 Paolillo R, Burch P. Infantile contracture of the inferior rectus. Am f Ophthalmol 1969;67:204.

8 Lyle TK. Surgical managment of congenital muscle-fascial anomalies in strabismus. St Louis: CV Mosby, 1970.

9 Hupp SL, Williams JP, Curran JE. Computerized tomography in the diagnosis of the congenital fibrosis syndrome. $\mathcal{F}$ Clin Neuro-ophthalmol 1990;10:135-9.

characterised by the medial or lateral recti being fibrosed causing a fixed esotropia or exotropia. ${ }^{10}$ Vertical retraction syndrome has been described as retraction of the globe in downgaze due to fibrosis of the vertical recti. ${ }^{11}$ Congenital fibrosis of the inferior recti is characterised by involvement of the inferior recti alone or with the levator muscle. ${ }^{12} 1317$ This condition may be unilateral or bilateral.

While the degree of phenotypic homogeneity in families previously reported in the literature is high, it is of particular interest that congenital ptosis of the inferior rectus coexists in our second family with severe general fibrosis. This suggests that these two entities are the result of an identical mutation and argues against the separate clinical classification that has hitherto
10 Villaseca A. Strabismus fixus. Am f Ophthalmol 1959;48: 751-62.

11 Gillies WE, Harris AJ, Brooks AMV, et al. Congenital fibrosis of the vertically acting extraocular muscles. Ophthalmolsis of the vertically acting

12 Von Noorden GK. Congenital heredical ptosis with inferior rectus fibrosis. Arch Ophthalmol 1970;83:378.

13 Tandon RK, Burke JP, Strachan IM. Unilateral congenital fibrosis syndrome presenting with hypotropia. Acta Oph-

14 Apt L, Axelrod R. Generalized fibrosis of the extraocular

15 Engle EC, Kunkel LM, Specht LA, et al. Mapping a gene for congenital fibrosis of the extraocular muscles to the centro73

16 Engle EC, Marondel I, Houtman WA, et al. Congenital fibrosis of the extraocular muscles (autosomal dominant congenital external ophthalmoplegia): genetic homogeneity, linkage refinement, and physical mapping on chromosome 12. Am f Hum Genet 1995;57:1086-94.

17 Duke-Elder SS, Wybar K. Ocular motility and strabismus. St Louis: CV Mosby, 1973:476. thalmol 1993;71:860-2. muscles. Am F Ophthalmol 1978;85:822-9. meric region of chromosome 12. Nature Genet 1994;7:69- 